\title{
Young adult males' motivators and perceived barriers towards eating healthily and being active: a qualitative study
}

\author{
Lee M Ashton ${ }^{1}$, Melinda J Hutchesson ${ }^{1}$, Megan E Rollo ${ }^{1}$, Philip J Morgan², Debbe I Thompson ${ }^{3}$
} and Clare E Collins ${ }^{1 *}$

\begin{abstract}
Background: There is a lack of understanding of young men's perspectives in obesity-related research. This study aims to: (1) identify young men's perceived motivators and barriers in adopting healthy eating and physical activity behaviours, and (2) explore any differences in responses by weight status categories.

Methods: Ten focus groups (32-63 minutes; 3-9 participants per group) were conducted with 61 young men (BMI: $25.3 \pm 5.1 \mathrm{~kg} / \mathrm{m}^{2}$, aged: 18-25 years) from the Hunter region, New South Wales, Australia. There were 35 (57.4\%) healthy weight men and 26 (42.6\%) overweight/ obese men. Three groups were with healthy weight participants, three with overweight/obese participants and four with mixed-BMI participants. Sessions were audio-recorded and transcribed. Data analysis was conducted by an independent researcher using NVIVO10.

Results: Motivators for healthy eating grouped into four themes: physical health (e.g. to live longer), sport or performance (e.g. to support their sporting goals), physical appearance (e.g. sexual attractiveness) and social influences (e.g. societal expectations to eat healthy), while key motivators for physical activity were: physical appearance (e.g. sexual attractiveness), social inclusion (e.g. making friends), physical and mental health (e.g. relieve stress) and improvements for sport or performance (e.g. improve fitness). Themes for key barriers to eating healthy were: intrinsic (e.g. perceived effort to adopt healthy eating), logistic (e.g. cost), and social factors (e.g. peer influence), while busy lifestyles (e.g. lack of time), logistic (e.g. cost), cognitive-emotional (e.g. feelings of inferiority) and social factors (e.g. family upbringing) were key barriers for physical activity. Responses varied little by BMI status.

Conclusion: This research emphasises the importance of consulting young men when developing healthy lifestyle programs that aim to promote healthy eating and physical activity in young men. Future research is needed to identify the most effective ways to address their motivators and barriers in intervention research.
\end{abstract}

Keywords: Young men, Focus groups, Qualitative research, Physical activity, Healthy eating, Obesity, Health behaviour

\section{Background}

Young adult men (aged 18-25 years) are entering a key transitional life phase. During this time period many personal, social and environmental changes transpire such as moving away from home [1], starting tertiary education [1], cohabitation with peers or partners [1],

\footnotetext{
* Correspondence: clare.collins@newcastle.edu.au

'School of Health Sciences, Faculty of Health and Medicine, Priority Research Centre in Physical Activity and Nutrition, University of Newcastle, Callaghan, Australia

Full list of author information is available at the end of the article
}

and beginning employment [2]. These changes can be associated with unhealthy lifestyle behaviours such as weight gain [3], poor dietary behaviours [4, 5] and sedentary lifestyles $[6,7]$.

Globally, young men have a higher prevalence of overweight and obesity compared to young women ( $18 \%$ vs $\sim 17 \%)$ and these differences are more pronounced in developed countries ( $\sim 37 \%$ vs $\sim 29 \%)$ [8]. This is mirrored in Australia ( $42 \%$ vs $35 \%$ ) [9], which is not surprising given that almost half (48\%) of young Australian men fail to meet national physical activity

\section{Biomed Central}


recommendations and approximately $97 \%$ fail to consume adequate intakes of fruit and vegetables daily [9]. Of particular concern is the steep trajectory of weight gain starting at 18 years, such that by age 35-39 years nearly $60 \%$ of males from developed countries are classed as overweight or obese [8]. Once established obesity is hard to treat; a recent systematic review confirmed only 14 out of 56 interventions achieved significant results for weight loss maintenance $(>5 \%$ of initial weight loss) [10]. Therefore prevention of obesity is critical.

A Danish study in young men found that those who were obese at age 20 years were twice as likely to die by age 55 years than their non-obese counterparts and had an 8year shorter life expectancy [11]. This highlights the critical importance of addressing key obesity prevention lifestyle behaviours in men whilst they are still young.

Programs have been implemented that target health risk behaviours (e.g. diet and physical activity) in young men, but many utilize a 'one-size fits all' approach [12]. This is problematic because males and females differ, as they are likely to have unique perceived motivators and barriers to modifying their lifestyle behaviours [13]. The limited knowledge of young men's perspectives in obesity-related research has been gathered from studies in university/college students with samples overrepresented by women $[14,15]$.

In a recent systematic review of health-related interventions that recruited young men only (Ashton et al 'unpublished observations'), none reported using a participatory approach, indicating that the interventions were designed without taking into account young men's perceived motivators and barriers. Interventions designed without the perspective of the target audience are at risk of having decreased engagement, adherence and impact [16]. The value of a participatory approach is its potential to bridge gaps between research and practice by identifying key motivators and barriers to healthy lifestyle choices, ultimately enabling the design of a more tailored intervention [17].

There is a general lack of understanding as to why young men do not engage in health interventions and how to design a program that appeals to them. Few studies have addressed this. A qualitative study in the US explored college students' barriers to weight management [18] and split the sessions by sex. The focus group sessions containing only young men identified intrapersonal (e.g. lack of discipline), interpersonal (e.g. social situations) and environmental (e.g. time constraints) barriers. Similarly, another qualitative study in the US [19] explored both motivators and barriers to healthy weight maintenance in young male college students. The barriers identified were comparable to Greaney et al [18], but additional barriers included lifestyle obligations, influence of female partners on sedentary behaviours and disliking the taste of healthy foods. Motivators were generally centred on appearance (e.g. to be more attractive), addressing medical issues (e.g. long term health) and achieving sporting goals [19]. However, both of these studies were conducted with university student populations from the US, and thus may not provide a broad representation of motivators and barriers. A recent focus group study in rural, Australian, [20] overweight and obese young men recruited from various community settings aimed to explore attitudes towards losing weight. Although the strict population specifications resulted in a small sample size $(n=30)$, valuable information was obtained. The young men said being overweight or obese was the 'norm' in today's society and thus did not feel the need to change. Environmental factors (e.g. price and convenience of fast food) were identified as key barriers to changing weight status.

This current study aims to build on this limited evidence base by reporting results of focus groups conducted in a sample of young men aged 18 to 25 to: 1) identify perceived motivators and barriers in adopting healthy eating and physical activity behaviours and 2) explore any differences in responses by weight status categories.

\section{Methods}

The conduct and reporting of this paper adhered to the guidelines outlined in the consolidated criteria for reporting qualitative research (COREQ) [21]. Ethical approval was obtained from the University of Newcastle Human Research Ethics Committee.

\section{Study design}

A qualitative design using a focus group methodology was applied as they are an ideal way to explore young men's perceived motivators and barriers to healthy behaviours. This approach was selected because focus groups can be undertaken in naturalistic settings as opposed to experimental situations [22] which may stimulate more openness and candour [23]. Also the group interaction has the capability to elicit information and insights that are less accessible during individual interviews [24]. Probing by the moderator allowed in depth exploration of unanticipated issues as well as an opportunity to clarify and enhance understanding of responses [23].

\section{Participants and setting}

Eligible participants included: male and aged between 18 and 25 years who were fluent in reading, writing and speaking in English. Young men were selected using a purposive sampling method (i.e. homogenous on a particular characteristic; in this case it was for gender and age) and recruited from the local university, technical colleges (TAFE) and the community. Recruitment materials included: flyers distributed around the university 
and technical college campuses, a media release (newspaper, local radio and social media) and advertising on social media (Facebook). Interviews continued until the moderator felt that data saturation was achieved and this was confirmed during data analysis. Interested individuals were asked to complete an online eligibility screen. Eligible individuals were contacted via email. Demographic characteristics were collected during the online eligibility screen including self-reported height and weight which were used to calculate BMI. Consented participants were allocated to a focus group session based on BMI status; three groups consisted of healthy weight males (BMI: 18.5-24.9 $\mathrm{kg} / \mathrm{m}^{2}$ ), three were with overweight/obese participants (BMI: $\geq 25.0 \mathrm{~kg} / \mathrm{m}^{2}$ ), while the remaining four groups consisted of mixed-BMI participants. Focus groups were conducted in a private venue at the university or technical college. Participants received a $\$ 25$ gift voucher to cover time and travel costs.

\section{Data collection}

Each focus group contained between 3-9 participants, with focus groups lasting between 32 to 63 minutes. All groups were conducted by the first author (LMA) who at the time of the study was a PhD student and classed as a young male (aged 25 years). The interviewer received detailed training in focus group methodology by a highly experienced practitioner (DIT). An assistant moderator (male, aged 27 years) attended all sessions to aid with note-taking and time management. No relationship between the interviewer and participants was established prior to study. All participants provided written informed consent.

The structured discussion framework was developed by the research team to facilitate discussion and reflection around the overall aims of the qualitative study. The questions were generated using the Krueger and Casey's method for 'five categories of questions' [25] which include an opening question, introductory question, transition questions, key questions and a concluding question. After review of the literature, the content of questions was informed by the questions from similar studies in young men $[18,19]$; these were then pretested with small groups of young men and revisions made where necessary. A total of eleven questions were asked but only the responses to four questions are included in this paper. Specifically the included questions explored participants' motivators and barriers to healthy eating and physical activity. Probes were used to clarify, and explore the topics. In the closing minutes of each focus group session a verbal summary of responses was provided to participants by the moderator. Participants were asked to review the summary and then had the option to provide any other additional comments that may have been missed. Once the participants had departed, both the moderator and assistant moderator had a brief discussion to compare notes and ensure the perceptions of responses were the same.

\section{Data analysis}

The focus groups were digitally recorded with the participants' consent and transcribed verbatim. A computer program (NVIVO 10) was used to assist with the organisational aspects of data analysis. Analysis was conducted by an independent qualitative researcher. A hybrid approach of inductive and deductive analysis was adopted [26] allowing for an in-depth exploration of data-driven, as well as theory driven concepts. A coding template was developed a-priori based on the research questions which was then applied to the data with the intent of identifying meaningful units of text. The coding scheme was revised and further expanded during coding, as new inductive codes were assigned to segments of data describing a new theme. Following coding of all focus group transcripts, themes and patterns in the data were identified and connected into an explanatory framework, clustered under headings that directly related to the research questions. This interpretative phase enabled the generation of overarching and sub-themes which were felt to capture the multifaceted views, experiences and insights of participants. All themes are presented in weighted order with the most frequently mentioned first.

\section{Results}

Sixty one young men (mean age: $20.8 \pm 2.3$ years) from the Hunter region, New South Wales, Australia participated in 10 focus groups (average 6.1 participants per group). Of these 35 (57.4\%) were healthy weight and 26 (42.6\%) were either overweight or obese. Participants were predominantly single $(91.8 \%)$ and approximately half were university students $(52.5 \%)$ (Table 1$)$.

\section{Factors motivating young men to engage in healthy eating}

Young men were asked; "Please tell me a few reasons why young men like you might want to eat healthier foods?" Four themes emerged: 1) physical health; 2) sport or performance; 3) physical appearance and 4) social influences. The themes did not differ by weight status and are therefore reported combined.

\section{Physical health}

Most participants mentioned health or medical benefits as a reason for eating healthier foods. This included both short-term benefits (e.g., general body functioning and immune system) and long-term benefits (e.g., increasing life expectancy). As one participant said: "Well I guess when you eat healthier you... well your body functions better and you feel better..." (overweight/ obese). Another 
Table 1 Demographic characteristics of young adult men $(n=61)$

\begin{tabular}{|c|c|}
\hline Characteristic & $\begin{array}{l}\text { Mean } \pm S D \\
\text { or } n(\%)\end{array}$ \\
\hline Age (years) & $20.8 \pm 2.3$ \\
\hline \multicolumn{2}{|l|}{ Employment status } \\
\hline Student (University) & $32(52.5 \%)$ \\
\hline Student (technical college) & $14(22.9 \%)$ \\
\hline Working full time paid employment & $10(16.4 \%)$ \\
\hline Casual employment & $3(4.9 \%)$ \\
\hline Unemployed & $2(3.3 \%)$ \\
\hline \multicolumn{2}{|l|}{ Highest Qualification } \\
\hline School certificate (Year 10 or equivalent) & $3(4.9 \%)$ \\
\hline Higher school certificate (Year 12 or equivalent) & $40(65.6 \%)$ \\
\hline Trade/ apprenticeships & $1(1.6 \%)$ \\
\hline Certificate/ diploma (e.g. childcare, technician) & $8(13.1 \%)$ \\
\hline University degree & $9(14.8 \%)$ \\
\hline \multicolumn{2}{|l|}{ Income } \\
\hline No income & $13(21.3 \%)$ \\
\hline$\$ 1-\$ 199$ per week, $(\$ 1-\$ 10,399$ per year) & $6(9.8 \%)$ \\
\hline$\$ 200-\$ 299$ per week, $(\$ 10,400-\$ 15,599$ per year $)$ & $16(26.2 \%)$ \\
\hline$\$ 300-\$ 399$ per week, $(\$ 15,600-\$ 20,799$ per year $)$ & $3(4.9 \%)$ \\
\hline$\$ 400-\$ 599$ per week, $(\$ 20,800-\$ 31,199$ per year $)$ & $2(3.3 \%)$ \\
\hline$\$ 600-\$ 799$ per week, $(\$ 31,200-\$ 41,599$ per year $)$ & $1(1.6 \%)$ \\
\hline$\$ 800$ - $\$ 999$ per week, $(\$ 41,600-\$ 51,999$ per year $)$ & $2(3.3 \%)$ \\
\hline$\$ 1,000-\$ 1,249$ per week, $(\$ 52,000-\$ 64,999$ per year $)$ & $3(4.9 \%)$ \\
\hline$\$ 1,250-\$ 1,499$ per week, $(\$ 65,000-\$ 77,999$ per year $)$ & $2(3.3 \%)$ \\
\hline$\$ 1,500-\$ 1,999$ per week, $(\$ 78,000-\$ 103,999$ per year $)$ & $1(1.6 \%)$ \\
\hline Did not Know & $10(16.4 \%)$ \\
\hline Did not want to answer & $2(3.3 \%)$ \\
\hline \multicolumn{2}{|l|}{ Marital status } \\
\hline Single & $56(91.8 \%)$ \\
\hline Defacto & $4(6.6 \%)$ \\
\hline Married & $1(1.6 \%)$ \\
\hline Height (m) & $1.8 \pm 0.6$ \\
\hline Weight (kg) & $81.1 \pm 16.7$ \\
\hline Body mass index $\left(\mathrm{kg} / \mathrm{m}^{2}\right)$ & $25.3 \pm 5.1$ \\
\hline \multicolumn{2}{|l|}{ BMI category } \\
\hline Healthy weight & $35(57.4 \%)$ \\
\hline Overweight & $17(27.9 \%)$ \\
\hline Obese & $9(14.7 \%)$ \\
\hline
\end{tabular}

said: "longevity too so like living longer, not getting sick as often" (healthy weight).

\section{Sport or performance}

Young men were also motivated to eat healthier to complement athletic/sporting goals or other lifestyle pursuits. As one participant stated: "Oh yes to support their goals in the gym or in sport is the primary reason for a lot of my mates" (overweight/obese) while another said: "To perform better like at sport and like at work" (overweight/obese).

\section{Physical appearance}

Many young men acknowledged the positive impact healthy eating had on improving their physical appearance and attractiveness to potential partners. In particular the potential to lose weight and be more appealing and attractive to others seemed to be especially important. For instance one young man said: "To look good and attract the women" (overweight/obese).

\section{Social influences}

Social influences on healthier eating were divided into two sub-themes. Social inclusion emerged, with many young men discussing the positive expectations attached to healthy eating: "I just kind of feel like it's what's you're supposed to do, like it's just that thing you know you're supposed to be doing when it comes to food" (overweight/obese). Also social environment, including peers and family were influential on food choices: "Yeah like if your parents are health nuts whatever then you'll grow up as wanting that stuff" (overweight/obese).

\section{Factors motivating young men to undertake physical activity}

Participants were asked: "Please tell me a few reasons why young men like you might want to be more physically active?" Responses were divided into four themes: 1) physical appearance; 2) social inclusion; 3) physical and mental health and 4) sport or performance. Each is discussed below. Similar to healthy eating, themes did not differ by BMI status.

\section{Physical appearance}

Amongst the most frequently mentioned motivators were factors relating to body image, such as "getting a hot body" (overweight/obese) and ultimately becoming more attractive to others, particularly the opposite sex: "I think a lot of people are motivated by aesthetics and looking good with the hope to attract a partner probably" (overweight/obese).

\section{Social inclusion}

Physical activity was viewed by many as providing an important context for gaining social acceptance, making friends and improving one's standing amongst peers (i.e., impressing others and gaining popularity). As one participant said: "The social aspect of getting involved in a sporting club and spending time with your mates, all that sort of stuff" (overweight/obese) 


\section{Physical and mental health}

The motivators to undertaking physical activity were similar to the motivators identified for healthy eating, with frequent reference to improving overall physical health and the effect this may have on longevity. However the motivators to physical activity included more emphasis on the mental health benefits associated with physical activity, particularly by its stress relieving and 'feel-good' potential through the effect of endorphins and adrenaline, or simply through the pure enjoyment of physical activity. For instance one participant reported: "Feel better like endorphins and all that razzmatazz" (healthy weight).

\section{Sport or performance}

Many young men were motivated by the prospect of developing new sport skills: with common examples including: "to build on strength" (healthy weight) and "to improve fitness" (overweight/obese). They were also motivated by the sense of achievement associated with mastery of the new physical skill: "... and there's something motivational about learning a new sport as well or a new you know like surfing, skateboarding whatever if you're not good at it and you start mastering it, it's kind of motivational to keep going with it" (healthy weight).

\section{Barriers to healthy eating}

Participants were asked: "Please tell me a few reasons why young men might not eat healthy already?" All groups raised issues that broadly fell into three themes: 1) factors intrinsic to the person; 2) logistic factors and 3) social factors.

\section{Factors intrinsic to the person}

Amongst the intrinsic barriers mentioned, the perceived effort required to adopt healthy eating patterns was amongst the most commonly mentioned. Healthy foods were perceived to require a greater degree of planning and preparation; as one young man said: "It certainly takes much more time to think about preparing a balanced diet for a week and hitting everything, all the food groups and a variety of foods and preparing that all and stuff which, I guess if you are busy, you're not going to prioritise it, there's always something else more urgent" (overweight/obese).

There were differences in responses for some of the intrinsic factors by BMI status; only healthy weight young men reported lack of knowledge and lack of skills required in relation to buying, preparing and cooking healthy foods. As one participant said: "I think another big one is not knowing how to prepare such foods, I think there's lots of various healthy foods that you just don't know what to do with them most of the time" (healthy weight). Although this barrier was mentioned by healthy weight men, it did not appear to be specific to them i.e., it appeared that their perception was that this was thought to be a general barrier faced by all young men when attempting to eat healthy, regardless of weight status.

\section{Logistic factors}

Participants in most focus groups identified access and cost as key logistic barriers. Overall, unhealthier foods were perceived by the majority to incur lesser costs with one participant providing the example of the ubiquitous "\$2 McDonalds burger" (overweight/obese) and as being omnipresent in society: "in terms of fast foods like you can quickly get them and they're easy to obtain generally" (overweight/obese).

\section{Social factors}

Many young men identified important social barriers to adopting healthy eating. The most commonly mentioned were the social context within which most eating occurred, emphasising the role that peers especially had on the choice of foods consumed; as one participant reported: "I think depending on like the situation or whatever, quite a lot of like what we would be doing is eating, is more of a social type thing so when we are eating, we're eating in a group and it's not like "Hey, come over, let's all have a salad together" (overweight/obese). In addition many young men acknowledged the societal expectations placed upon them which did not support a healthy diet such as male stereotypes and the stigma attached to eating healthy foods, as one young man said: "It [healthy eating] goes against the sort of stereotypical masculine image in society" (overweight/obese).

\section{Barriers to physical activity}

Participants were asked: "Please tell me a few reasons why young men might not be physically active already?" four themes emerged: 1) busy lifestyles; 2) logistic factors; 3 ) cognitive-emotional factors and 4) social factors. Participants listed similar physical activity barriers regardless of BMI status, although there was a trend in the data for participants in the healthy weight groups to discuss barriers in a more hypothetical manner, while those in the overweight/obese groups often discussed barriers in a more personal context.

\section{Busy lifestyles}

Almost all participants mentioned busy lifestyles as a key barrier; in this context lack of time, lack of motivation, lack of commitment and influence of other competing leisure activities were relayed as very prominent obstacles contributing to a busy lifestyle. As a result young men often prioritised other activities/commitments ahead of physical activity: "I'd say lack of time for me, I have a lot of other things to do and I kind of tend to push physical activity like right down to the bottom of the list"(healthy weight). 


\section{Logistic factors}

As was the case for barriers to healthy eating; almost all participants mentioned cost and access as key barriers to physical activity. Particularly access to a variety of sporting activities and the costs associated with gym membership and equipment, as one young man said: "I didn't join the University Tennis Club for first year because I just didn't have the money for a hundred a semester" (overweight/obese).

\section{Cognitive-emotional factors}

Many young men often felt that doing exercise or going to the gym was associated with feelings of inferiority, inadequacy, lack of self-confidence and feeling self-conscious or embarrassed. Negative stereotypes and the stigma attached to the gym activities were also frequently mentioned: "I just hate the idea of firstly people yelling at me and them people with Spandex" (overweight/obese).

Many participants also talked of having unrealistic goals. Not being able to achieve such goals or finding that one is not as good at an activity as expected was seen as a deterrent to future physical activity. As one participant responded: "Sometimes you try to be physically active and then you're not quite that good and so you...like you try and overdo it at first and then you kind of regress and just go back to doing nothing because you couldn't do everything"(healthy weight).

\section{Social factors}

Many young men identified the influence of peers, social group membership (i.e. university student) and family upbringing as barriers to physical activity. As one participant said: "if your friends don't work out and go to the gym, it's unlikely that you'll go" (overweight/obese) and another said: "Past times, just how you grew up, if you grew up watching $T V$ well you're going to watch $T V$ " (overweight/obese).

\section{Discussion}

The aims of this qualitative study were to provide an indepth insight into young men's facilitators and barriers to healthy eating and physical activity and to explore any differences in responses by weight status category. The dominant motivating themes to eating healthier foods included; improving physical health, complementing sport or performance, improving physical appearance, and social influences (e.g. positive family influence). Similar motivating themes were apparent for undertaking physical activity including; improving physical appearance, social inclusion, improving physical and mental health, and improving sport related skills or performance.

The leading barriers to healthy eating as identified by young men include: factors intrinsic to the person, logistic (e.g. cost and access) and social factors. Perceived barriers to physical activity include: busy lifestyles (e.g. lack of time), logistic (e.g. cost and access), cognitive-emotional and social factors. There were minimal differences in the responses for all questions between young men classified as healthy weight and those classed as overweight/obese.

The current findings are mostly consistent with Walsh et al [19] where young male college students reported similar physical health benefits (e.g. long-term health), complementing sporting performance and physical appearance benefits (e.g. sexual attractiveness) as key motivating themes to healthy eating. This is also apparent for physical activity motivators with similar themes identified, such as improvements in physical health (e.g. current/future health), mental health (e.g. to improve state of mind), sporting skills (e.g. fitness) and physical appearance (e.g. attractiveness). The high proportion of single young men in the Walsh et al [19] study (87\%) is comparable to the current study $(92 \%)$ and may explain why both identified attractiveness to future partners as a key theme. However unlike the current study, no social motivating themes arose for either physical activity or healthy eating in their analysis. This needs be explored further to determine whether social inclusion and positive influences of peers and family can motivate young men to improve health behaviours.

The perceived barriers influencing healthy eating and physical activity in the current study support earlier research that lifestyle factors (e.g. time constraints [18, 19] and other obligations, such as job and education schedule [19]), social factors (e.g. peer influence [20]) and logistic factors (e.g. lack of access to healthy foods and high costs associated with healthy behaviours [18, 20]) are major influences. Whilst current findings confirm these key barriers, additional social barriers (e.g. stereotypes placed upon young men), cognitiveemotional barriers (e.g. feelings of inferiority when doing physical activity) and intrinsic barriers (e.g. perceived effort to adopt healthy eating) were also identified. The additional responses in the current study may be due to the larger sample or the inclusion of young men with different socio-demographic characteristics. Of the three other studies, two were conducted in university/college students from the US $[18,19]$ and one in rural Australian young men [20] whereas the current study includes young men from a range of sociodemographic backgrounds; for example, although $75 \%$ of the current sample were students, $23 \%$ were from technical colleges whereby a distinguishing feature is an over-representation of students from low socio-economic areas [27]. This is also reflected by the low average income rates of the young men (between $\$ 14,963-\$ 21,170$ per annum) when compared to the national average income for young Australian men aged 15-24 years (\$27,671 per annum) [28]. 
Notably, young men in the current study identified social factors as both motivators (e.g. social inclusion) and as barriers (e.g. peer influence) to healthy eating and undertaking physical activity. Similarly Mendis et al. [20] found young men reported that social activities with peers can impact negatively on food choices but also found that social support is required to motivate them into making positive lifestyle behaviour changes. The positive and negative aspects of social influences must be considered in future healthrelated interventions with young men, with attempts made to specifically focus on the positive aspects such as social support and social inclusion. At the same time, counteracting the negative aspects of peer influence (e.g. on unhealthy eating habits) is imperative. A potential way of addressing this would be to target the social group; results of metaanalytic reviews confirmed individuals were more likely to adhere to exercise programs if they participated with others in social or group-based settings rather than on their own $[29,30]$ and increased total energy expenditure when supported by friends or family [31].

Surprisingly, there were very few differences in the responses by weight status. This suggests that there are either no differences in young male's perspectives by BMI status, or could potentially be due to inaccurate selfreporting of weight status [32] and thus some participants could have been stratified into the wrong group. However a recent study has demonstrated the validity of online self-report of height and weight by young adults [33]. In addition, BMI does not reflect muscle mass content [34], young men with a greater muscle mass may have been stratified into the overweight/obese group and the responses by these individuals may have suppressed the comments from young men who have a higher fat mass. Also several overweight or obese young men only wanted to attend sessions with their healthy weight friends (hence the mixed-BMI group sessions). This may have resulted in some overweight/obese young men mirroring responses to appease or agree with their healthy weight friends out of a desire to "fit in".

The European Commission on Men's Health recently highlighted that the behavioural differences between men and women represent different needs and perceived barriers in terms of health promotion and intervention design [13]. To some extent this is supported in the responses from the current study as motivators (e.g. to develop sporting skills) and barriers (e.g. male stereotypes and stigma attached to healthy foods) unique to young men were identified, that were not identified in online surveys of young Australian women [35, 36]. Whilst there are similarities for motivators (e.g. to improve physical and mental health) and barriers (e.g. time constraints and cost) to weight change in young women these may be due to age related factors as both sexes are experiencing similar transitional phases in their life such as; starting tertiary education
$[1,37]$ cohabitation with peers or partners [1] and less financial stability (compared to older adults) particularly for Australian young adults where full-time employment rates are at their lowest since records began in 1986 [37]. The age-related differences are apparent when compared to similar studies with mostly middle-aged and older men [38-41]. Unlike the responses from this current study, improving appearance and sport skills (e.g. fitness) were perceived as less important motivators to exercise in older men (aged 40-55 years) [38]. Although there were some similarities such as improving health [38], older age groups of men were mainly motivated to exercise and lose weight to become more effective in their work role [38, 40]. In contrast to the responses from young men in the current study, negative influences from peers and logistic factors (e.g. cost) were not seen as barriers in older age groups of men [39-41]. Lifestyle differences between the age groups (e.g. occupational status, housing environment, family circumstances, marital status) may be attributable to these differences in barriers [42].

Early research has linked masculinities with young men's health, often associating hegemonic masculinity with poorer health behaviours [43, 44]. Hegemonic masculinity is not a fixed entity but is often used to describe men who align with masculine ideals (e.g. strength, aggression, courage, independence, physical risk and being emotionally strong) $[45,46]$. This hegemonic 'macho' masculinity was exhibited by several young men in the current study; for example, one young man said: "It [healthy eating] goes against the sort of stereotypical masculine image in society" (overweight/obese). Whilst another nonchalantly discussed many of the risk behaviours that they undertook: "...and if you're having more alcohol I'm going to have some drugs" (overweight/obese). Recent research on masculinities have confirmed that young men are now constructing post-modern masculine identities because of changes to youth culture, leisure patterns and employment and there is a move away from the conventional hegemonic masculinity to a more pluralistic interpretation [2]. Gender tailored interventions (i.e. those designed to address the individual characteristics of persons within a sample, such as personality factors, goals, needs, preferences, and resources [47]) have the potential to address the social diversity and plurality of masculinities in young men [48]. Previous research has shown gender tailoring to be effective in improving health outcomes and recruiting, retaining and engaging men [49-51]. However, these studies were generally conducted in middle-aged and older men and therefore there is a need to test this in young men [12].

\section{Implications for research and practice}

Healthy lifestyle programs that incorporate nutrition and physical activity for young men should be designed to address their motivators and offset their perceived 
Table 2 Potential strategies to inform development of programs aiming to address motivator and barrier themes to healthy eating and physical activity

\begin{tabular}{|c|c|}
\hline Theme & Potential strategies to address each theme \\
\hline \multicolumn{2}{|l|}{$\begin{array}{l}\text { Motivators for } \\
\text { healthy eating }\end{array}$} \\
\hline Physical Health & $\begin{array}{l}\text {-Emphasise both proximal (e.g. improved energy } \\
\text { levels) and distal health benefits (e.g. prevention } \\
\text { of chronic diseases) of healthy eating in program } \\
\text { messaging and recruitment strategies. }\end{array}$ \\
\hline \multirow[t]{2}{*}{$\begin{array}{l}\text { Sport or } \\
\text { performance }\end{array}$} & $\begin{array}{l}\text {-Nutrition educators to inform of ways in which } \\
\text { certain foods and healthy eating can improve } \\
\text { sporting performance and work related activity. }\end{array}$ \\
\hline & $\begin{array}{l}\text { Provide daily meal plans of their sporting role } \\
\text { models and how this contributes to different } \\
\text { areas of performance (e.g. healthy foods to } \\
\text { consume pre-workout or healthy foods to help } \\
\text { with recovery) }\end{array}$ \\
\hline Physical appearance & $\begin{array}{l}\text {-Recruitment strategies and messaging to focus } \\
\text { on ways the program can improve appearance } \\
\text { e.g. to improve muscle mass. }\end{array}$ \\
\hline \multirow[t]{2}{*}{ Social influences } & $\begin{array}{l}\text {-Target social groups/circles and have group- } \\
\text { based sessions }\end{array}$ \\
\hline & $\begin{array}{l}\text {-Tailor recruitment strategies to social groups e.g. } \\
\text { "bring-a-mate" }\end{array}$ \\
\hline
\end{tabular}

Motivators for

physical activity

Physical appearance -Recruitment strategies to focus on ways program can improve appearance e.g. improve muscle mass

Social inclusion $\quad \cdot$ Target social groups/ circles and have groupbased sessions

Physical and mental -Emphasise both proximal and distal benefits of health

Sport or performance

\section{Barriers to healthy}

eating

Intrinsic

Logistic

Social factors

Barriers to physical activity
Table 2 Potential strategies to inform development of programs aiming to address motivator and barrier themes to healthy eating and physical activity (Continued)

\begin{tabular}{|c|c|}
\hline Busy lifestyles & $\begin{array}{l}\text {-Flexibility in intervention delivery mode: for } \\
\text { example, intervention sessions could be face-to- } \\
\text { face but also video recorded to allow young men } \\
\text { to attend in-person or relay the video recording } \\
\text { at a time most convenient for them }\end{array}$ \\
\hline \multirow[t]{2}{*}{ Logistic } & $\begin{array}{l}\text {-Increased access to fitness facilities (e.g. improve } \\
\text { knowledge of outdoor workout equipment ) or } \\
\text { home-based fitness equipment }\end{array}$ \\
\hline & -Promote exercise that does not need equipment \\
\hline Cognitive-emotional & $\begin{array}{l}\text {-Intervention facilitators to provide young men } \\
\text { with encouragement and positive reinforcement. }\end{array}$ \\
\hline Social factors & $\begin{array}{l}\text {-Target social groups/ circles and have group- } \\
\text { based sessions }\end{array}$ \\
\hline
\end{tabular}

barriers to facilitate behaviour change. Table 2 provides a list of potential program components, program messaging and recruitment strategies for a tailored program for young males to address the key themes emanating from the current study.

\section{Strengths and limitations}

The strengths of this study include; (1) a relatively large and diverse sample $(n=61)$ when compared to other similar studies in young men [18-20] and (2) the segmenting of focus groups by BMI status.

Limitations of the current study include; (1) the lack of diversity of the sample for employment status, with an overpopulation of students and (2) even though lower income rates were apparent, we did not assess alternative sources of income (e.g. student loans, parental support) and therefore unable to establish if the sample is truly economically disadvantaged. (3) The focus group questions were less personalized (referring to young men in general rather than themselves) to elicit openness in responses but this meant we were unable to determine if these motivators and barriers were experienced by the participants themselves or were more a perception of the experiences of young men in general. This may explain why few differences were identified by weight status categories. (4) Although responses were stratified by BMI, we did not separate by young male subgroups (e.g. unemployed, students, fathers etc) and future research may consider this to inform development of programs aiming to individually tailor content to specific subgroups of young men.

\section{Conclusions}

Young men are classed as a 'hard to reach group' and are difficult to engage in preventive health interventions $[13,52]$. Unique motivators and barriers for young 
men in the current research, which differ to studies in different ages and sex population samples, emphasise the importance of consulting young men to inform development of healthy lifestyle programs that aim to target them for the promotion of healthy eating and physical activity. These findings suggest that future interventions targeting physical activity and healthy eating for young men should include strategies to promote benefits relating to physical health, mental health, physical appearance, sport/ performance, and social influences of physical activity and healthy eating to facilitate engagement. Addressing key intrinsic, lifestyle, cognitive-emotional, logistic and social barriers to healthy eating and physical activity may help engage this target group. Future research is needed to identify the most effective ways to address these motivators and barriers within interventions.

\section{Competing interests}

The authors declare that they have no competing interests.

\section{Authors' contributions}

LMA made a substantial contribution to the conception, design and implementation of the study and drafting of the manuscript. MJH, MER, PJM, DIT and CEC contributed to the methodological design of the study including assisting with developing focus group questions, designing recruitment materials, protocol development and revision of the manuscript. All authors read and approved the final manuscript.

\section{Acknowledgements}

We would like to thank the independent qualitative researcher (Vibeke Hansen) for undertaking the data analysis and for the assistant moderator (Elroy Aguiar) who helped with time-keeping and note-taking for each focus group session. This research project was funded by a 3D Healing Walk grant provided by Hunter Medical Research Institute (HMRI). L. M. Ashton undertook this research as a part requirement for the degree of PhD (Nutrition and Dietetics), The University of Newcastle, Australia. L. M. Ashton is supported by an International Postgraduate Award Scholarship and The Greaves Family Medical Research Scholarship through HMRI. M.J Hutchesson is supported by a Postdoctoral Research Fellowship from the National Heart Foundation of Australia (\#100177).

\section{Author details}

${ }^{1}$ School of Health Sciences, Faculty of Health and Medicine, Priority Research Centre in Physical Activity and Nutrition, University of Newcastle, Callaghan, Australia. ${ }^{2}$ School of Education, Faculty of Education and Arts, Priority Research Centre in Physical Activity and Nutrition, University of Newcastle, Callaghan, Australia. ${ }^{3}$ USDA/ARS Children's Nutrition Research Center, Department of Pediatrics, Baylor College of Medicine, Houston, USA.

Received: 20 April 2015 Accepted: 4 July 2015

Published online: 15 July 2015

\section{References}

1. Poobalan AS, Aucott LS, Precious E, Crombie IK, Smith WC. Weight loss interventions in young people (18 to 25 year olds): a systematic review. Obes Rev. 2010;11(8):580-92.

2. Mullen K, Watson J, Swift J, Black D. Young men, masculinity and alcohol. Drugs Educ Prev Policy. 2007;14(2):151-65.

3. Racette SB, Deusinger SS, Strube MJ, Highstein GR, Deusinger RH. Weight changes, exercise, and dietary patterns during freshman and sophomore years of college. J Am Coll Health. 2005;53(6):245-51.

4. Irazusta A, Hoyos I, Irazusta J, Ruiz F, Díaz E, Gil J. Increased cardiovascular risk associated with poor nutritional habits in first-year university students. Nutr Res. 2007;27(7):387-94
5. Li K-K, Concepcion RY, Lee H, Cardinal BJ, Ebbeck V, Woekel E, et al. An examination of sex differences in relation to the eating habits and nutrient intakes of university students. J Nutr Educ Behav. 2012;44(3):246-50.

6. Anderson LM, Quinn TA, Glanz K, Ramirez G, Kahwati LC, Johnson DB, et al. The effectiveness of worksite nutrition and physical activity interventions for controlling employee overweight and obesity: a systematic review. Am J Prev Med. 2009;37(4):340-57.

7. Keating XD, Guan J, Piñero JC, Bridges DM. A meta-analysis of college students' physical activity behaviors. J Am Coll Health. 2005;54(2):116-26.

8. Ng M, Fleming T, Robinson M, Thomson B, Graetz N, Margono C, et al. Global, regional, and national prevalence of overweight and obesity in children and adults during 1980-2013: a systematic analysis for the Global Burden of Disease Study 2013. Lancet. 2014:384(9945):766-81.

9. Australian Bureau of Statistics. Australian Health Survey: First results 2011-2012. [http://www.abs.gov.au/ausstats/abs@.nsf/Lookup/ 4364.0.55.001main+features12011-12]

10. Collins CE, Neve M, Morgan P, Fletcher K, Williams R, Young M, et al. Effectiveness of interventions with a dietary component on weight loss maintenance: a systematic review. The JBI Database of Systematic Reviews and Implementation Reports. 2013;11(8):317-414.

11. Zimmermann $E_{1}$ Holst C, Sørensen T. Lifelong doubling of mortality in men entering adult life as obese. Int J Obes. 2011;35(9):1193-9.

12. Ashton LM, Hutchesson MJ, Rollo ME, Morgan PJ, Collins CE. A scoping review of risk behaviour interventions in young men. BMC Publ Health. 2014;14(1):957.

13. White A, De Sousa, B., De Visser, R., Hogston, R., Aage Madsen, S., Makara, P., Richardson, N. and Zatonski, W: The State of Men's Health in Europe: European Commision: The State of Men's Health in Europe: Extended report. 2011:1-407. http://ec.europa.eu/health/population_groups/docs/ men_health_extended_en.pdf.

14. Grubbs L, Carter J. The relationship of perceived benefits and barriers to reported exercise behaviors in college undergraduates. Fam Community Health. 2002;25(2):76-84.

15. Poobalan AS, Aucott LS, Clarke A, Smith WCS. Physical activity attitudes, intentions and behaviour among 18-25 year olds: A mixed method study. BMC Publ Health. 2012;12(1):640.

16. Hagen $\mathrm{P}$, Collin $\mathrm{P}$, Metcalf A, Nicholas M, Rahilly K, Swainston N, et al. Participatory Design of evidence-based online youth mental health promotion, intervention and treatment. Melbourne: Young and Well Cooperative Research Centre; 2012.

17. Cargo M, Mercer SL. The value and challenges of participatory research: Strengthening its practice. Annu Rev Public Health. 2008;29:325-50.

18. Greaney ML, Less FD, White AA, Dayton SF, Riebe D, Blissmer B, et al. College students' barriers and enablers for healthful weight management: a qualitative study. J Nutr Educ Behav. 2009;41(4):281-6.

19. Walsh JR, White AA, Greaney ML. Using focus groups to identify factors affecting healthy weight maintenance in college men. Nutr Res. 2009;29(6):371-8

20. Mendis K, Forster T, Paxton K, Hyland K, Yelverton J, McLean R, et al. Large and forgotten in rural Australia: assessment, attitudes and possible approaches to losing weight in young adult males. BMC Publ Health. 2014;14(1):243

21. Tong A, Sainsbury P, Craig J. Consolidated criteria for reporting qualitative research (COREQ): a 32-item checklist for interviews and focus groups. Int J Qual Health Care. 2007;19(6):349-57.

22. Johnson RB, Onwuegbuzie AJ. Mixed methods research: A research paradigm whose time has come. Educ Res. 2004;33(7):14-26.

23. Krueger R: Focus Groups: A Practical Guide for Applied Research 2nd edn. California, USA: Sage; 1994.

24. Morgan DL, Kreuger RA. 'When to use focus groups and why'. In: Morgan DL, editor. Successful Focus Groups. London: Sage; 1993.

25. Krueger R, Casey M. Focus Groups: A Practical Guide for Applied Research. 4th edn. California, USA: Sage; 2009

26. Fereday J, Muir-Cochrane E. Demonstrating rigor using thematic analysis: A hybrid approach of inductive and deductive coding and theme development. Int J Qual Meth. 2008;5(1):80-92.

27. Foley P: The Socio-Economic Status of Vocational Education and Training Students in Australia: National Centre for Vocational Education Research (NCVER): Adelaide, Australia 2007.

28. Australian Bureau of Statistics: 5673.0.55.003 - Wage and Salary Earner Statistics for Small Areas, Time Series, 2005-06 to 2010-11: [http://www.abs.gov.au/AUSSTATS/abs@.nsf/DetailsPage/ 5673.0.55.0032005-06\%20to\%202010-11?OpenDocument] 
29. Carron AV, Hausenblas HA, Mack D. Social influence and exercise: A meta-analysis. Int J Sport Exerc Psychol. 1996;18:1-16.

30. Dishman R, Buckworth J. Increasing physical activity: a quantitative synthesis. Med Sci Sports Exerc. 1996;28(6):706-19.

31. Treiber FA, Baranowski T, Braden DS, Strong WB, Levy M, Knox W. Social support for exercise: relationship to physical activity in young adults. Prev Med. 1991;20(6):737-50.

32. Gorber SC, Tremblay M, Moher D, Gorber B. A comparison of direct vs. self-report measures for assessing height, weight and body mass index: a systematic review. Obes Rev. 2007;8(4):307-26.

33. Pursey K, Burrows TL, Stanwell P, Collins CE. How Accurate is Web-Based Self-Reported Height, Weight, and Body Mass Index in Young Adults? J Med Internet Res. 2014;16(1):e4.

34. Rothman KJ. BMI-related errors in the measurement of obesity. Int J Obes. 2008;32:S56-9.

35. Andajani-Sutjahjo S, Ball K, Warren N, Inglis V, Crawford D. Perceived personal, social and environmental barriers to weight maintenance among young women: a community survey. Int J Behav Nutr Phys Activ. 2004;1(1):15.

36. Holley T, Collins CE, Morgan PJ, Callister R, MJ. H: Weight expectations, motivations for weight change, and perceived factors influencing weight management among young women: A cross-sectional study. Public Health Nutrition In press.

37. Stanwick J, Lu T, Rittie T, Circelli M: How young people are faring in the transition from school to work. European Commision: The State of Men's Health in Europe: Extended report. The Foundation for Young Australians (FYA); 2014. http://ec.europa.eu/health/population_groups/docs/ men_health_extended_en.pdf.

38. Hankey CR, Leslie WS, Lean ME. Why lose weight? Reasons for seeking weight loss by overweight but otherwise healthy men. Int J Obes Relat Metab Disord. 2002;26(6):880-2.

39. Morgan PJ, Warren JM, Lubans DR, Collins CE, Callister R. Engaging men in weight loss: Experiences of men who participated in the male only SHED-IT pilot study. Obes Res Clin Pract. 2011;5(3):e239-48.

40. Sabinsky MS, Toft U, Raben A, Holm L. Overweight men's motivations and perceived barriers towards weight loss. Eur J Clin Nutr. 2007;61(4):526-31.

41. Schutzer KA, Graves BS. Barriers and motivations to exercise in older adults. Prev Med. 2004;39(5):1056-61.

42. World Health Organization. Men, ageing and health: Achieving health across the life span. Geneva: World Health Organization; 2001. p. 1-63.

43. Eisler RM. The relationship between masculine gender role stress and men's health risk: The validation of a construct. In: Levant RF, Pollack WS, editors. A new psychology of men. New York: BasicBooks; 1995. p. 207-25.

44. O'Neil JM, Good GE, Holmes S. Fifteen years of theory and research on men's gender role conflict: New paradigms for empirical research. In: Levant RF, Pollack WS, editors. A new psychology of men. New York: BasicBooks; 1995. p. 164-206.

45. Connell RW, Messerschmidt JW. Hegemonic masculinity rethinking the concept. Gend Soc. 2005;19(6):829-59.

46. Young K, White $P$. Researching sports injury: Reconstructing dangerous masculinities. Research on men and masculinities series. 2000;13:108-26.

47. Beck C, McSweeney JC, Richards KC, Roberson PK, Tsai P-F, Souder E. Challenges in tailored intervention research. Nurs outlook. 2010;58(2):104-10.

48. Kreuter MW, Farrell DW, Olevitch LR, Brennan LK. Tailoring health messages: Customizing communication with computer technology. New York: Routledge; 2013.

49. Morgan PJ, Callister R, Collins CE, Plotnikoff RC, Young MD, Berry N, et al. The SHED-IT community trial: A randomized controlled trial of internet-and paper-based weight loss programs tailored for overweight and obese men. Ann Behav Med. 2013;45(2):139-52.

50. Morgan PJ, Collins CE, Plotnikoff RC, Callister R, Burrows T, Fletcher R, et al. The 'Healthy Dads, Healthy Kids' community randomized controlled trial: A community-based healthy lifestyle program for fathers and their children. Prev Med. 2014;61:90-9.
51. Hunt K, Wyke S, Gray CM, Anderson AS, Brady A, Bunn C, et al. A gender-sensitised weight loss and healthy living programme for overweight and obese men delivered by Scottish Premier League football clubs (FFIT): a pragmatic randomised controlled trial. Lancet. 2014;383(9924):1211-21.

52. Zwolinsky S, McKenna J, Pringle A, Daly-Smith A, Robertson S, White A. Optimizing lifestyles for men regarded as 'hard-to-reach'through top-flight football/soccer clubs. Health Educ Res. 2013;28(3):405-13.

\section{Submit your next manuscript to BioMed Central and take full advantage of:}

- Convenient online submission

- Thorough peer review

- No space constraints or color figure charges

- Immediate publication on acceptance

- Inclusion in PubMed, CAS, Scopus and Google Scholar

- Research which is freely available for redistribution 